Bài báo khoa học

\title{
Đánh giá ảnh hưởng của các hồ chứa đến dòng chảy trên sông Đà
}

\section{Bùi Huyền Linh ${ }^{1}$, Trần Anh Phương ${ }^{\text {* }}$}

${ }^{1}$ Viện Khoa học tài nguyên nước, Bộ Tài nguyên và Môi trường; wri@ monre.gov.vn; phuongtran.monre@gmail.com; linhb.dctv@gmail.com.

*Tác giả liên hệ: phuongtran.monre@gmail.com; Tel.: +84-961776683

Ban Biên tập nhận bài: 12/8/2021; Ngày phản biện xong: 8/9/2021; Ngày đăng bài: $25 / 11 / 2021$

Tóm tắt: Nghiên cứu này đánh giá ảnh hưởng của các hồ chứa trong và ngoài lãnh thổ đến sự thay đổi dòng chảy trên sông Đà đến trạm Tạ Bú bằng phương pháp thống kê và sử dụng mô hình HEC-HMS mô phỏng dòng chảy tự nhiên bằng số liệu mưa vệ tinh (IMERG) so sánh với số liệu thực đo (khi các hồ đi vào hoạt động) để đánh giá sự thay đổi dòng chảy trong mùa lũ và mùa cạn và dòng chảy năm. Kết quả cho thấy sự suy giảm tổng lượng dòng chảy năm khi các hồ đi vào hoạt động làm tăng dòng chảy mùa cạn và giảm dòng chảy mùa lũ.

Từ khóa: Hồ chứa; Sông Đà; Dòng chảy; Ngoài lãnh thổ; Mưa vệ tinh; HEC-HMS.

\section{Mở đầu}

Lưu vực sông Hồng là lưu vực sông lớn thứ hai ở Việt Nam chỉ sau hệ thống sông Mê Công với tổng diện tích lưu vực khoảng $149.760 \mathrm{~km}^{2}$, trong đó $73,812 \mathrm{~km}^{2}$ nằm trong lãnh thổ nước ta và $75.948 \mathrm{~km}^{2}$ nằm ở nước ngoài. Sông Đà là chi lưu lớn nhất của sông Hồng, có diện tích lưu vực $52.900 \mathrm{~km}^{2}$, trong đó phần lưu vực ngoài lãnh thổ Trung Quốc chiếm 49\% diện tích lưu vực. Trước năm 2007, trên sông Đà chỉ có duy nhất thủy điện Hòa Bình được xây dựng và đi vào vận hành năm 1989 với công suất lắp máy $1.920 \mathrm{MW}$. Giai đoạn 2007-2009, trên dòng chính thuộc địa phận Trung Quốc có 11 công trình đã đi vào vận hành, phục vụ mục đích phát điện là chính. Từ năm 2010 đến nay, trên phần lãnh thổ Việt Nam, một số thuỷ điện lớn như thủy điện Sơn La, Lai Châu, Bản Chát và Huội Quảng được xây dựng và cũng đã đi vào hoạt động. Tuy nhiên, việc xây dựng và vận hành các hồ chứa trên sông Đà đã làm thay đổi chế độ dòng chảy tự nhiên trên sông, thay đổi hình thái lòng dẫn trên sông và làm ảnh hưởng đến môi trường sinh thái trên lưu vực. Vì vậy việc đánh giá ảnh hưởng của các hồ chứa này đến chế độ dòng chảy trên sông Đà là hết sức cần thiết.

Đánh giá sự thay đổi của chế độ dòng chảy do hoạt động của các hồ chứa đã và đang được các nhà nghiên cứu trong và ngoài nước thực hiện. Chẳng hạn, ở nước ngoài, [1] đánh giá tác động của Hồ chứa Tam Hiệp (TGR) đến chế độ dòng chảy và chuyển nước hạ du sử dụng mô hình dòng chảy tối giản. [2] sử dụng mô hình SWAT và WEAP đánh giá tác động của các hồ chứa và biến đổi khí hậu đến chế độ thủy văn của sông Sê San-Srêpôk. Kết quả nghiên cứu cho thấy việc vận hành hồ chứa làm tăng lưu lượng dòng chảy mùa khô và giảm lưu lượng dòng chảy mùa mưa. Biến đổi khí hậu có khả năng gây ra những thay đổi đáng kể trong dòng chảy, mặc dù những thay đổi này tương đối thấp hơn so với những thay đồi do vận hành hồ chứa gây ra. Trong nước, một số nghiên cứu đánh giá tác động của hệ thống hồ chứa thượng nguồn đến sự thay đổi thủy văn, thủy lực và lòng dẫn hạ du sông Mê Công [3-4]. Nghiên cứu đã phân tích đánh giá được các thay đổi dòng chảy hàng năm và lượng 
dòng chảy trong mùa khô về châu thổ Mê Công qua chuỗi số liệu lịch sử từ 1924 đến 2015, lượng hóa được các thay đổi dòng chảy mùa khô theo các giai đoạn, chứng minh sự gia tăng này do tác động điều tiết nước của các hồ chứa trên lưu vực từ mùa mưa sang mùa khô, đồng thời lượng hóa được các gia tăng điều tiết ở những năm gần đây (từ 2001 đến 2014). Trên lưu vực sông Hồng, có rất nhiều các nghiên cứu đánh giá tác động của hệ thống hồ chứa đến sự biến đổi chế độ thủy văn, thủy lực và lòng dẫn hạ du lưu vực sông ĐàThao-Lô [5-9]. Kết quả phân tích cho thấy sự biến đổi lớn về chế độ thủy văn lòng dẫn hạ du sau khi hệ thống hồ chứa thượng nguồn đi vào hoạt động. Trên sông Hồng, [6] nghiên cứu đánh giá tác động của hệ thống hồ chứa trên sông Đà, sông Lô đến dòng chảy mùa cạn hạ lưu sông Hồng và đề xuất giải pháp đảm bảo nguồn mở cho hạ du. Một số nghiên cứu sử dụng mô hình NAM được ứng dụng trong nghiên cứu đánh giá tác động của các hồ chứa Lai Châu, Sơn La và Hòa Bình đến dòng chảy mùa cạn trên sông Đà [10-11]. Trong nghiên cứu [12] đã đánh giá lượng dòng chảy sông Đà từ Trung Quốc vào Việt Nam phục vụ cho bài toán quy hoạch và quản lý tài nguyên nước sông Đà.

Các nghiên cứu trên đều chỉ ra sự thay đổi lớn của chế độ dòng chảy hạ lưu cả về mùa lũ và mùa cạn khi các hồ chứa đi vào vận hành điều tiết. Tuy nhiên, cho đến nay các nghiên cứu chỉ đánh giá sơ bộ ảnh hưởng của hệ thống hồ thượng lưu hoặc các hồ hạ lưu mà chưa phân tách, đánh giá ảnh hưởng của hệ thống các hồ trong và ngoài lãnh thổ Việt Nam. Đồng thời, các nghiên cứu đánh giá ảnh hưởng của hồ chứa đến sự thay đổi dòng chảy trên sông Đà thường dùng các phân tích thống kê từ số liệu thực đo tại các trạm thủy văn trên lưu vực với số liệu tương đối hạn chế. Trong nghiên cứu này, chúng tôi sẽ phân tách, đánh giá ảnh hưởng của các hệ thống hồ chứa trong và ngoài lãnh thổ Việt Nam đến chế độ dòng chảy sông Đà (đến trạm Tạ Bú), góp phần phục vụ công tác dự báo và quản lý tổng hợp tài nguyên nước trên lưu vực sông Đà sử dụng đồng thời phương pháp mô hình toán và phân tích thống kê. Nghiên cứu sử dụng kết hợp công cụ HEC-GeoHMS và mô hình thuỷ văn HEC-HMS để mô phỏng dòng chảy tự nhiên trên sông Đà từ số liệu mưa vệ tinh và số liệu bốc hơi tại trạm. Sau đó, sử dụng phương pháp phân tích thống kê, nghiên cứu so sánh, đánh giá sự khác biệt giữa dòng chảy tự nhiên và các giai đoạn khi các hồ trên lãnh thổ Trung Quốc và Việt Nam đi vào hoạt động, phục vụ đánh giá tác động của các hồ chứa đến chế độ dòng chảy trên sông Đà về tỉ lệ đóng góp mùa lũ, mùa cạn cũng như tổng lượng dòng chảy năm.

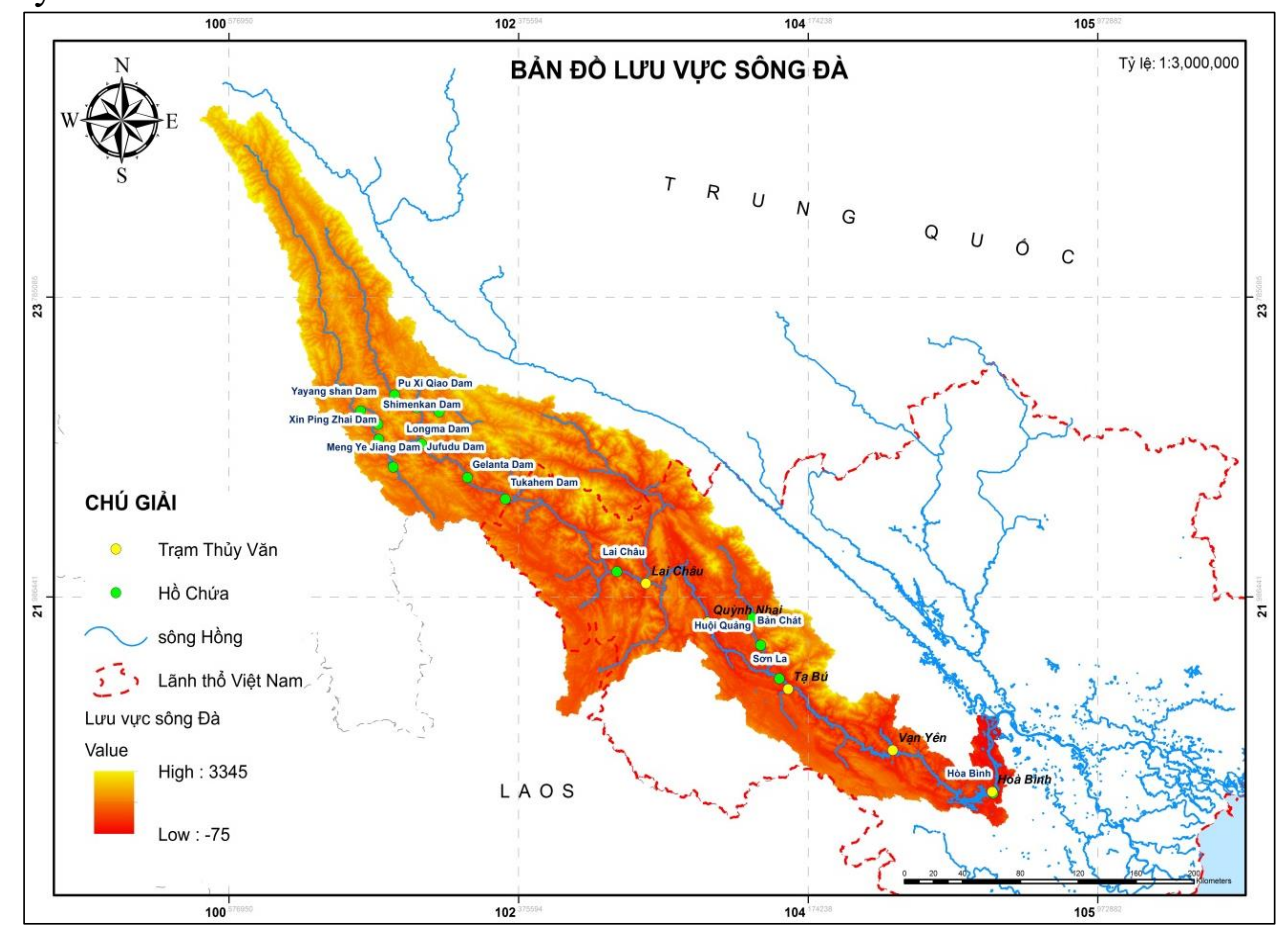

Hình 1. Bản đồ lưu vực sông Đà đến hồ Hoà Bình. 


\section{Phương pháp nghiên cứu}

\subsection{Phuơng pháp mô hình}

Để hoàn nguyên quá trình dòng chảy tự nhiên trên sông Đà, nghiên cứu sử dụng công cụ HEC-GeoHMS [13] và mô hình HEC-HMS [14] của Cục công binh Hoa Kỳ. Công cụ HEC-GeoHMS trên nền tảng ArcGIS được sử dụng để phân chia và tính toán các đặc trưng hình thái của các tiểu lưu vực cũng như thiết lập mạng lưới sông kết nối các tiểu lưu vực với nhau từ số liệu địa hình $\mathrm{DEM}$ với độ phân giải $30 \mathrm{~m}$. Các tiểu lưu vực và mạng lưới sông này sẽ được sử dụng trong mô hình HEC-HMS để mô phỏng quá trình mưa-dòng chảy trên lưu vực (Hình 2). HEC-HMS bao gồm nhiều phương pháp phục vụ cho nhiều mục đích khác nhau [15]. Phù hợp với nghiên cứu mô phỏng dòng chảy liên tục trong nhiều năm, trong nghiên cứu này chúng tôi lựa chọn sử dụng phương pháp SMA (Soil Moisture Accounting) để tính tổn thất, phương pháp đường đơn vị không thứ nguyên SCS để tính toán dòng chảy mặt tại cửa ra của lưu vực, phương pháp baseflow recession để diễn toán dòng chảy cơ sở và phương pháp Muskingum để diễn toán dòng chảy trên sông. Đầu vào của mô hình là chuỗi số liệu mưa và bốc hơi, đầu ra của mô hình là lưu lượng tại cửa ra của từng tiểu lưu vực và toàn lưu vực. Mô hình HEC-HMS đã được sử dụng ở rộng rãi ở Mỹ và nhiều nước trên thế giới do khả năng mô phỏng tương đối chính xác quá trình mưa-dòng chảy trên lưu vực, có giao diện người dùng thân thiện và là phần mềm mở [16-19].

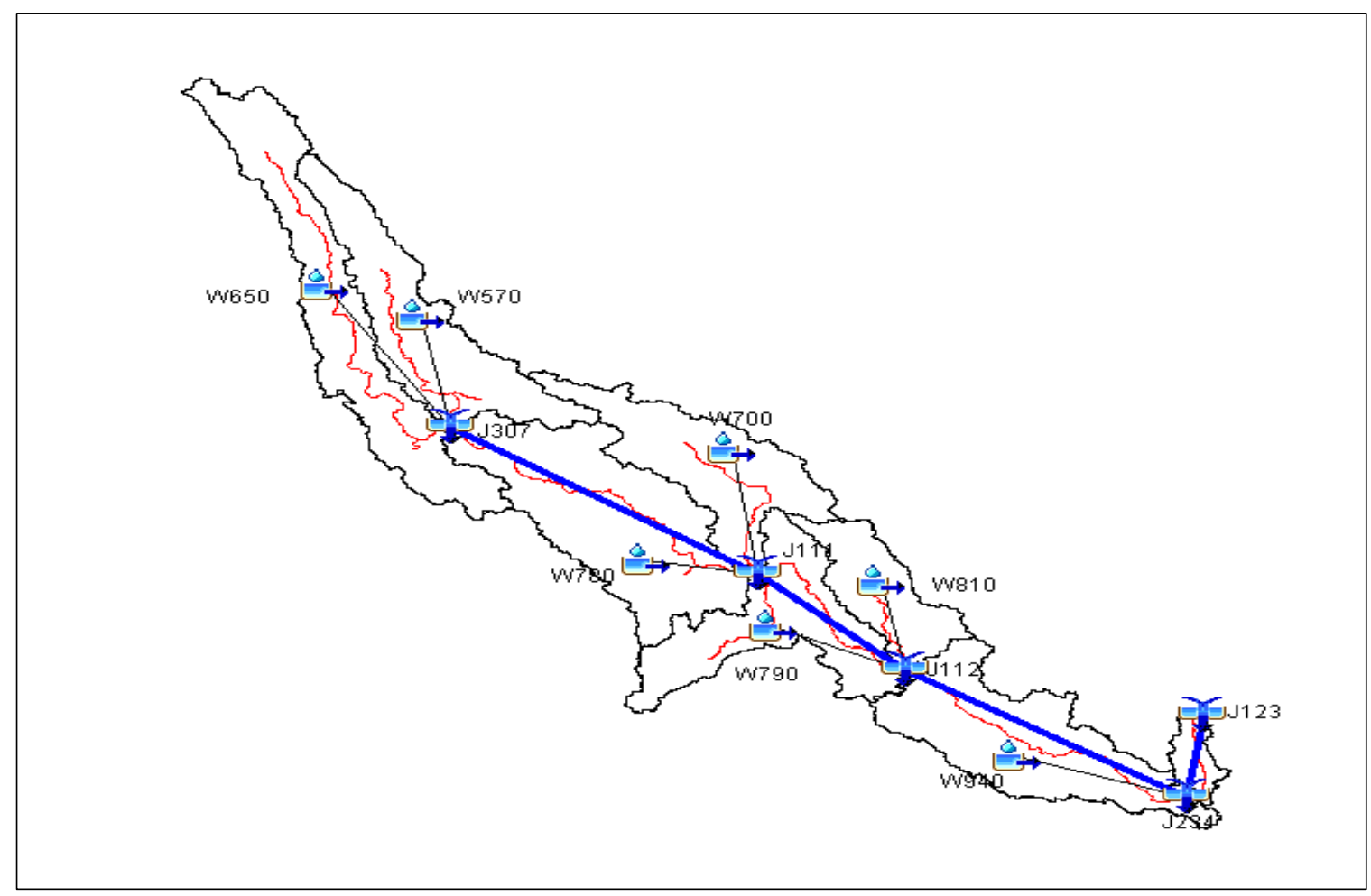

Hình 2. Sơ đồ phân chia các tiểu lưu vực trong mô hình HEC-HMS.

\subsection{Dũ liệu đầu vào mô hình}

Các số liệu dùng trong nghiên cứu bao gồm: số liệu DEM, các số liệu mưa vệ tinh, số liệu bốc hơi và số liệu lưu lượng đo tại các trạm khí tượng thủy văn trên lưu vực. Số liệu DEM dùng để phân chia các tiểu lưu vực và mạng lưới sông suối trên sông Đà là số liệu (Shuttle Radar Topography Mission - SRTM) của NASA có độ phân giải 30 m.

Số liệu đầu vào cho mô hình HEC-HMS là số liệu mưa vệ tinh IMERG và số liệu bốc hơi tại trạm trong giai đoạn 2003-2020. Số liệu bốc hơi được thu thập tại các trạm Lai Châu, Điện Biên và Mộc Châu.. Số liệu mưa dùng trong nghiên cứu là số liệu mưa vệ tinh 
toàn cầu IMERG (Integrated Multi-satellitE Retrievals for Global Precipittion Measurement) với độ phân giải $0.1^{\circ}$. Lý do sử dụng số liệu mưa vệ tinh toàn cầu IMERG trong nghiên cứu này là do mật độ các trạm đo mưa trên phần lãnh thổ Việt Nam tương đối thưa thớt và số liệu mưa trên phần lưu vực ngoài lãnh thổ không có. Số liệu mưa vệ tinh IMERG được xác định bằng cách kết hợp các quan trắc từ các vệ tinh của cơ quan vũ trụ Nhật Bản (JAXA) và cơ quan vũ trụ Mỹ (NASA) cũng như các cơ quan vũ trụ quốc tế khác [20], do đó được xem là một trong những nguồn dữ liệu mưa vệ tinh đáng tin cậy nhất hiện nay, tại Việt Nam có rất nhiều các nghiên cứu sử dụng số liệu mưa IMERG [21-22]. Đồng thời, nghiên cứu cũng thu thập số liệu lưu lượng tại các trạm Lai Châu và Tạ Bú từ 19612020 để hiệu chỉnh và kiểm định mô hình HEC-HMS cũng như đánh giá biến động chế độ dòng chảy do ảnh hưởng hoạt động của các hồ chứa.

\subsection{Các bước tiến hành}

Các bước tiến hành đánh giá ảnh hưởng của hệ thống các hồ chứa trên sông Đà đến chế độ dòng chảy được trình bày ở Hình 3 dưới đây. Sau khi mô hình mưa-dòng chảy trên sông Đà từ thượng lưu (bao gồm cả phần lưu vực ngoài lãnh thổ) đến trạm Tạ Bú được thiết lập, hiệu chỉnh và kiểm định, nghiên cứu sẽ sử dụng mô hình này hoàn nguyên quá trình dòng chảy tự nhiên, qua đó cùng với số liệu lưu lượng thực đo, so sánh, đánh giá ảnh hưởng của các hồ chứa đến chế độ dòng chảy trên sông Đà. Để phục vụ mục đích này, nghiên cứu tiến hành mô phỏng, so sánh ba giai đoạn:

Giai đoạn dòng chảy tự nhiên 1961-2006: Đây là thời kì dòng chảy từ thượng lưu đến trạm Tạ Bú không bị ảnh hưởng của hồ chứa ở cả trên lãnh thổ Trung Quốc và Việt Nam và được coi là giai đoạn nền để đánh giá ảnh hưởng của các hồ chứa đến chế độ dòng chảy.

Giai đoạn ảnh hưởng của hồ chứa: Ở giai đoạn này nghiên cứu xem xét các giai đoạn khác nhau tại các vị trí khác nhau. Tại trạm Lai Châu, nghiên cứu xem xét giai đoạn 20072014 (khi các hồ chứa Trung Quốc hoạt động) và giai đoạn 2015-2020 (khi có thêm hồ chứa Lai Châu đi vào hoạt động). Tại trạm Tạ Bú, nghiên cứu xem xét giai đoạn 20072020 khi các hồ chứa của cả Việt Nam và Trung Quốc đi vào hoạt động. Giai đoạn này sẽ được sử dụng để phân tích ảnh hưởng tổng hợp của các hồ chứa trong và ngoài nước đến sự thay đổi dòng chảy trên sông Đà.

\section{Kết quả và thảo luận}

\subsection{Hệ thống hồ chứa trên lư vực sông Đà được xem xét trong nghiên cưu}

Hệ thống hồ chứa trên sông Đà thuộc lãnh thổ Trung Quốc: Từ thượng nguồn sông Đà xuống gần biên giới nước ta có 11 công trình thủy điện đã xây dựng xong bao gồm các thủy điện: Chung Ái Kiều (Chongaiqiao), Phổ Tú Kiều (Puxiqiao), Tam Giang Khẩu (Sangjiangkou), Tứ Nam Giang (Shinanjiang), Tọa Dương Sơn (Yajiangsan), Thạch Môn Khảm (Si menkan), Tân Bình Trại (Xinpingsai), Long Mã (Long Ma), Phổ Độ (Jupudu), Cách lan tan (Gelantan) và Thổ Khả Hà (Tukate) (Hình 1). Các hồ chứa này có chiểu cao đập từ 60-135m; dung tích từ 80-590 triệu $\mathrm{m}^{3}$; công suất lắp máy dao động trong khoảng 68-450 MW. Tổng dung tích các hồ chứa nước khoảng 2,5 tỷ $\mathrm{m}^{3}$ [23].

Hệ thống hồ chứa sông Đà trên lãnh thổ Việt Nam: Hiện nay trên sông Đà phía Việt Nam nhiều hồ chứa thuỷ điện đã được xây dựng. Tuy nhiên, đa số là các hồ chứa nhỏ, chỉ có 3 hồ chứa lớn trên dòng chính sông Đà là hồ Hòa Bình (1989), Sơn La (2010) và Lai Châu (2015) và 2 hồ chứa trên dòng nhánh với công suất trên 200 MW là Bản Chát và Huội Quảng. Các hồ chứa này ngoài nhiệm vụ phát điện còn nhiệm vụ chống lũ cho hạ du và cấp nước phục vụ sản xuất và sinh hoạt. Vị trí một số hồ chứa lớn của cả Trung Quốc và Việt Nam được thể hiện ở Hình 1. 


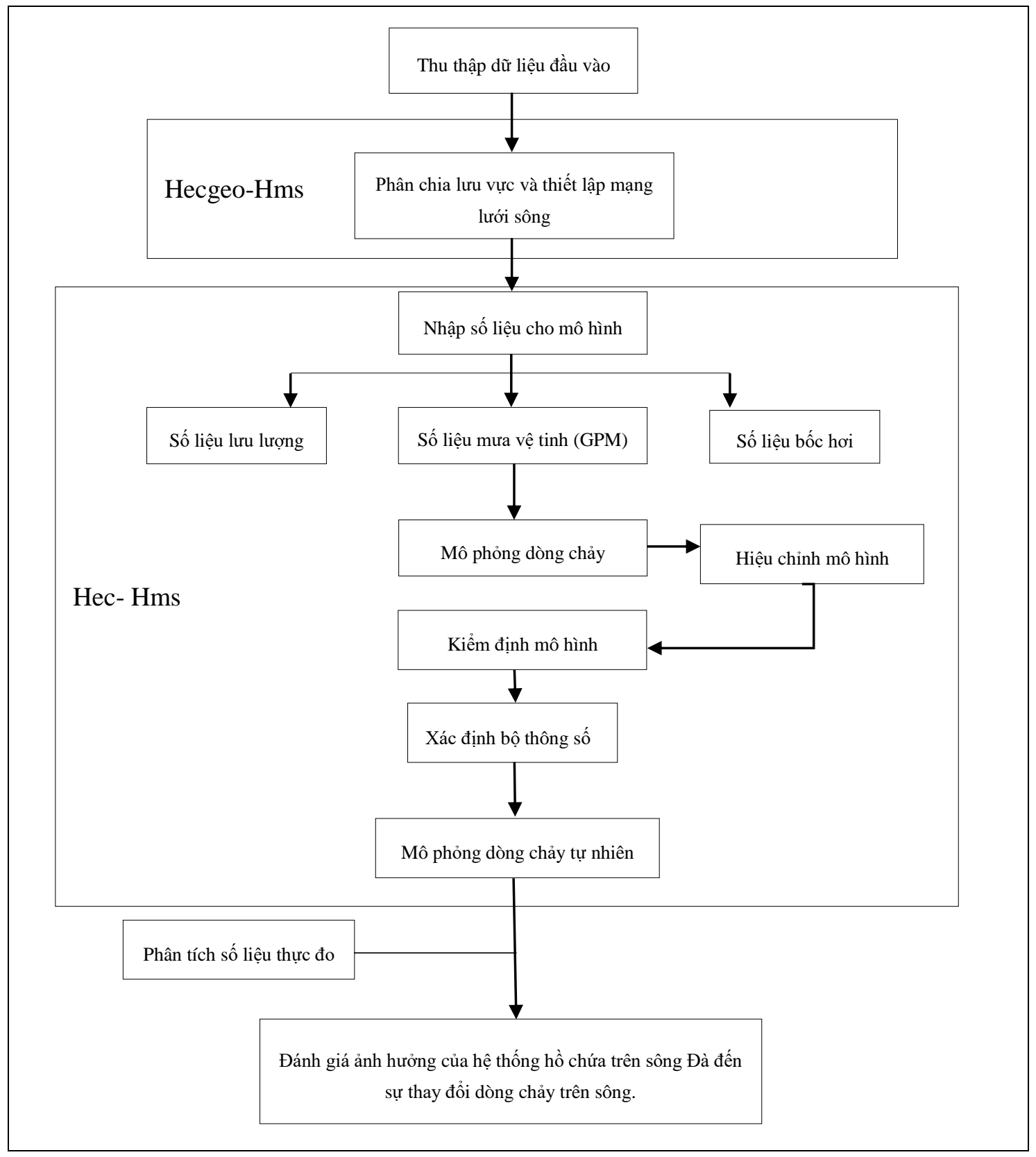

Hình 3. Sơ đồ các bước nghiên cứu.

\subsection{Kết quả hiệu chinh, kiểm định mô hình}

Nghiên cứu sử dụng số liệu trong giai đoạn 1/1/2003-31/12/2004 để hiệu chỉnh và 1/1/2005-31/12/2006 để kiểm định mô hình HEC-HMS. Hình 4-5 và Bảng 1 thể hiện kết quả hiệu chỉnh, kiểm định mô hình tại 2 trạm Lai Châu và Hòa Bình. Kết quả hiệu chỉnh, kiểm định cho thấy các trạm Tạ Bú, Lai Châu với chỉ số Nash, Pbias đều ở mức tốt cho thấy bộ mô hình hoàn toàn đáng tin cậy và phù hợp để mô phòng dòng chảy cho lưu vực sông Đà. Hình 4 và 5 cũng cho thấy mặc dù nhìn chung quá trình dòng chảy thực đo và tính toán phù hợp tương đối tốt, lưu lượng đỉnh lũ thực đo cao hơn mô phỏng. Nguyên nhân là do nghiên cứu sử dụng số liệu mưa ngày nên các đỉnh mưa trong ngày không được xem xét và do đó lưu lượng đỉnh lũ mô phỏng thấp hơn thực đo. Kết quả hiệu chỉnh, kiểm định cho phép chúng ta khẳng định số liệu mưa toàn cầu IMERG có chất lượng tương đối tốt và hoàn toàn có thể được sử dụng làm đầu vào cho mô hình mưa-dòng chảy ở những lưu vực thiếu hoặc không có số liệu. 

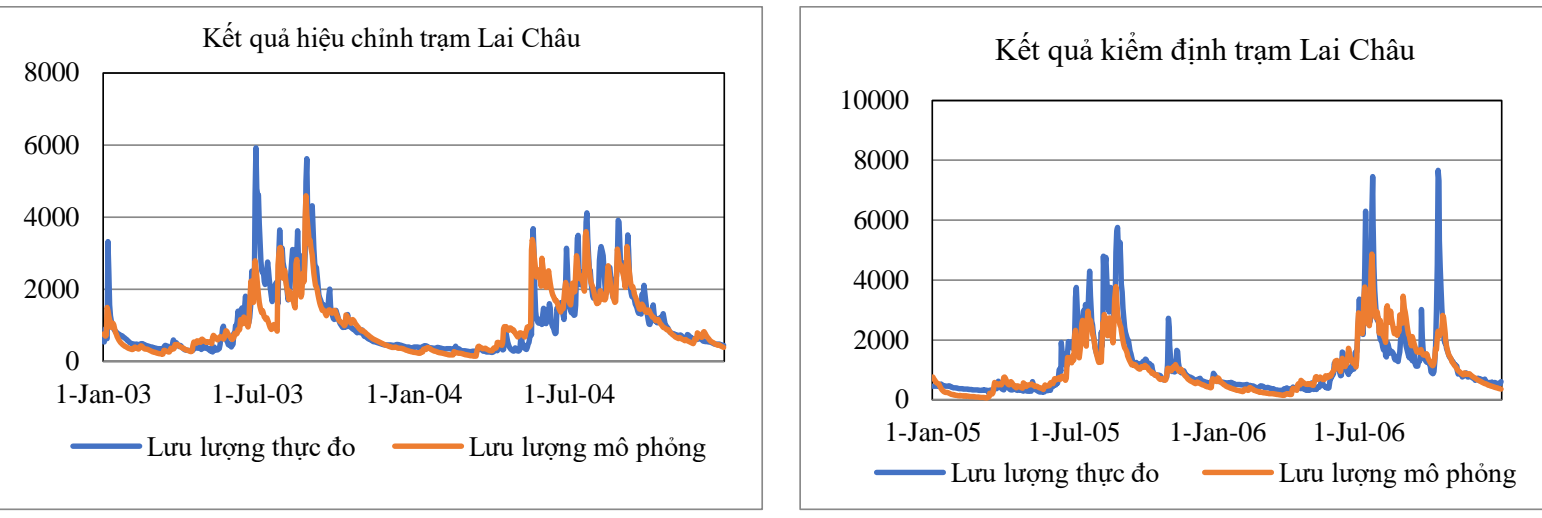

Hình 4. Kết quả hiệu chỉnh và kiểm định trạm Lai Châu.
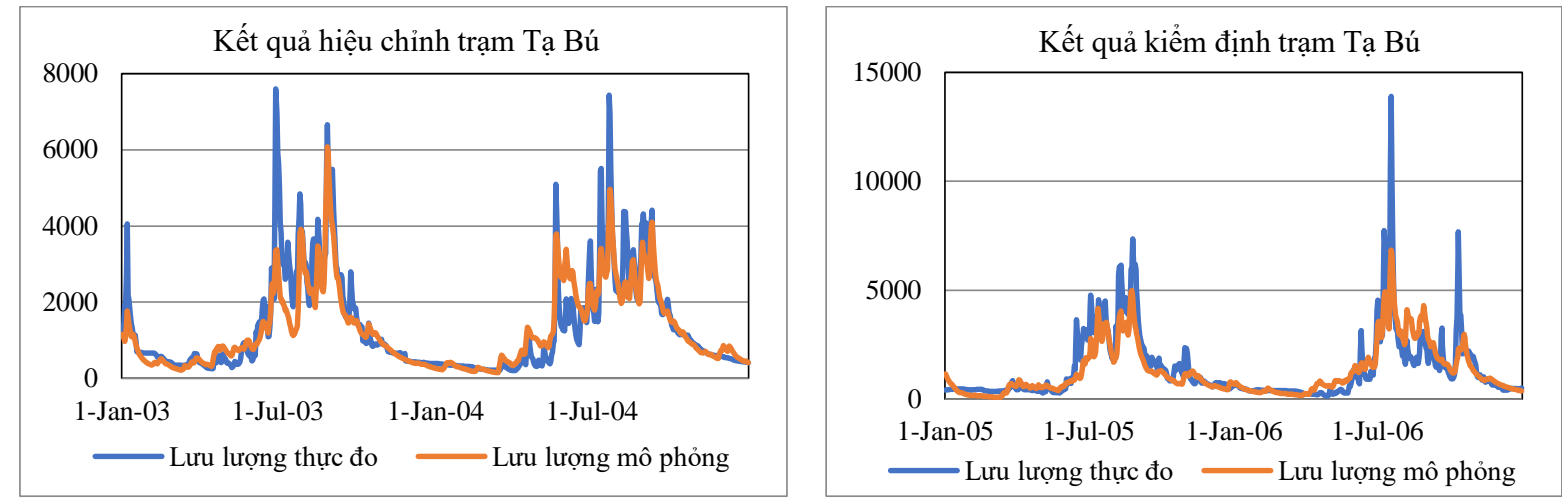

Hình 5. Kết quả hiệu chỉnh và kiểm định trạm Tạ Bú.

Bảng 1. Bảng kết quả hiệu chỉnh và kiểm định mô hình các trạm trên sông Đà.

\begin{tabular}{ccccc}
\hline \multirow{2}{*}{ Chỉ tiêu } & \multicolumn{2}{c}{ Trạm Tạ Bú } & \multicolumn{2}{c}{ Trạm Lai Châu } \\
\cline { 2 - 5 } & Hiệu Chỉnh & Kiểm Định & Hiệu Chỉnh & Kiểm Định \\
\hline Nash (NSE) & 0,818 & 0,749 & 0,756 & 0,711 \\
RMSE & 0,4 & 0,5 & 0,5 & 0,5 \\
PBIAS (\%) & $-1,00$ & $-4,57$ & 1,38 & $-5,74$ \\
\hline
\end{tabular}

3.3. Đánh giá ảnh hưởng của các hồ chứa Trung Quốc và Việt Nam đến chế độ dòng chảy trên sông Đà

Sau khi mô hình HEC-HMS được hiệu chỉnh và kiểm định, nghiên cứu sử dụng mô hình này mô phỏng, hoàn nguyên quá trình dòng chảy tự nhiên từ năm 2003 đến năm 2019 . Do thiếu số liệu thực đo thuộc phần lãnh thổ Trung Quốc nên nghiên cứu sử dụng các nguồn số liệu thực đo tại trạm Lai Châu để so sánh đánh giá ảnh hưởng của các hồ chứa Trung Quốc và sử dụng Trạm Tạ Bú để đánh giá ảnh hưởng của các hệ thống hồ chứa trên toàn lưu vực sông Đà. Hình 6 và 7 so sánh quá trình dòng chảy thực đo và dòng chảy tự nhiên mô phỏng tại các trạm Lai Châu và Tạ Bú. Ngoài các đường lưu lượng đo đạc và tính toán, các hình vẽ còn thể hiện hiệu số giữa lưu lượng đo đạc và tính toán tự nhiên $Q_{\text {tính toán tự }}$

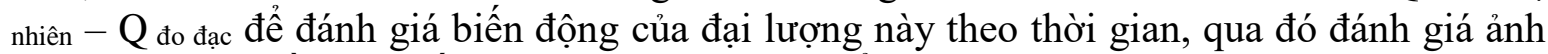
hưởng của các hồ chứa đến dòng chảy tự nhiên. Để đánh giá định lượng ảnh hưởng của các hồ chứa lên chế độ dòng chảy, nghiên cứu sử dụng chỉ số trung bình tuyệt đối của sai số tương đối tính theo công thức sau:

$$
\operatorname{SSTD}=\frac{1}{N} \sum_{\mathrm{i}=1}^{\mathrm{N}} \frac{\left|\mathrm{Q}_{\mathrm{obs}}^{\mathrm{i}}-\mathrm{Q}_{\text {sim }}^{\mathrm{i}}\right|}{\mathrm{Q}_{\mathrm{obs}}^{\mathrm{i}}}
$$


Trong đó SSTD là chỉ số trung bình tuyệt đối của sai số tương đối, $Q_{o b s}^{i}$ and $Q_{\text {sim }}^{i}$ lần lượt là lưu lượng đo đạc và mô phỏng tại thời điểm ith. $\mathrm{N}$ là độ dài chuỗi số liệu đánh giá. Có thể nhận thấy so với giai đoạn trước năm 2006, đại lượng Qtín toán tự nhiên - Qđo đạc các giai đoạn sau 2007 có sự biến đổi về lưu lượng với biên rộng hơn, đặc biệt về mùa lũ. Tại trạm Lai Châu, kết quả tính toán cho thấy thời kì đầu khi chưa có sự tác động của hồ chứa là thời kì dòng chảy tự nhiên (2003-2006) đường quá trình dòng chảy thực đo và mô phỏng khá trùng khớp, chỉ số Nash hiệu chỉnh và kiểm định trên 0,7 , chỉ số SSTD thời kì này là 0,32. Từ sau năm 2007 khi trên dòng chính phía thượng nguồn xây dựng các công trình hồ chứa, dòng chảy có sự thay đổi rõ nét (Hình 6). Chỉ số SSTD lên tới 0,48 trong giai đoạn 2007-2009 và 0.67 trong giai đoạn 2010-2019. Tại trạm Tạ Bú, giai đoạn 2003-2006 SSTD là 0,37 . Giai đoạn 2007-2009 khi các hồ Trung Quốc vận hành, SSTD là 0,41 . Từ năm 2010-2019, khi có thêm các hồ chứa ở nước ta đi vào hoạt động SSTD tăng lên 0,73. Điều này chứng tỏ khi các hồ chứa đi vào hoạt động quá trình dòng chảy tự nhiên trên sông Đà đã bị điều tiết tương đối mạnh. Các Hình 6 và 7 cũng cho thấy tổng lượng dòng chảy có sự suy giảm đáng kể đặc biệt về mùa lũ. Trong mùa lũ, đại lượng Qtính toán tự nhiên $-\mathrm{Q}_{\text {đo }}$ đạc (phần đồ thị dưới trục hoành) tăng dần qua từng giai đoạn với lượng giảm tương đối lớn,

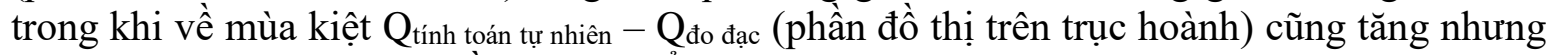
với lượng tăng nhỏ hơn nhiều. Do đó, tổng lượng dòng chảy năm giảm.

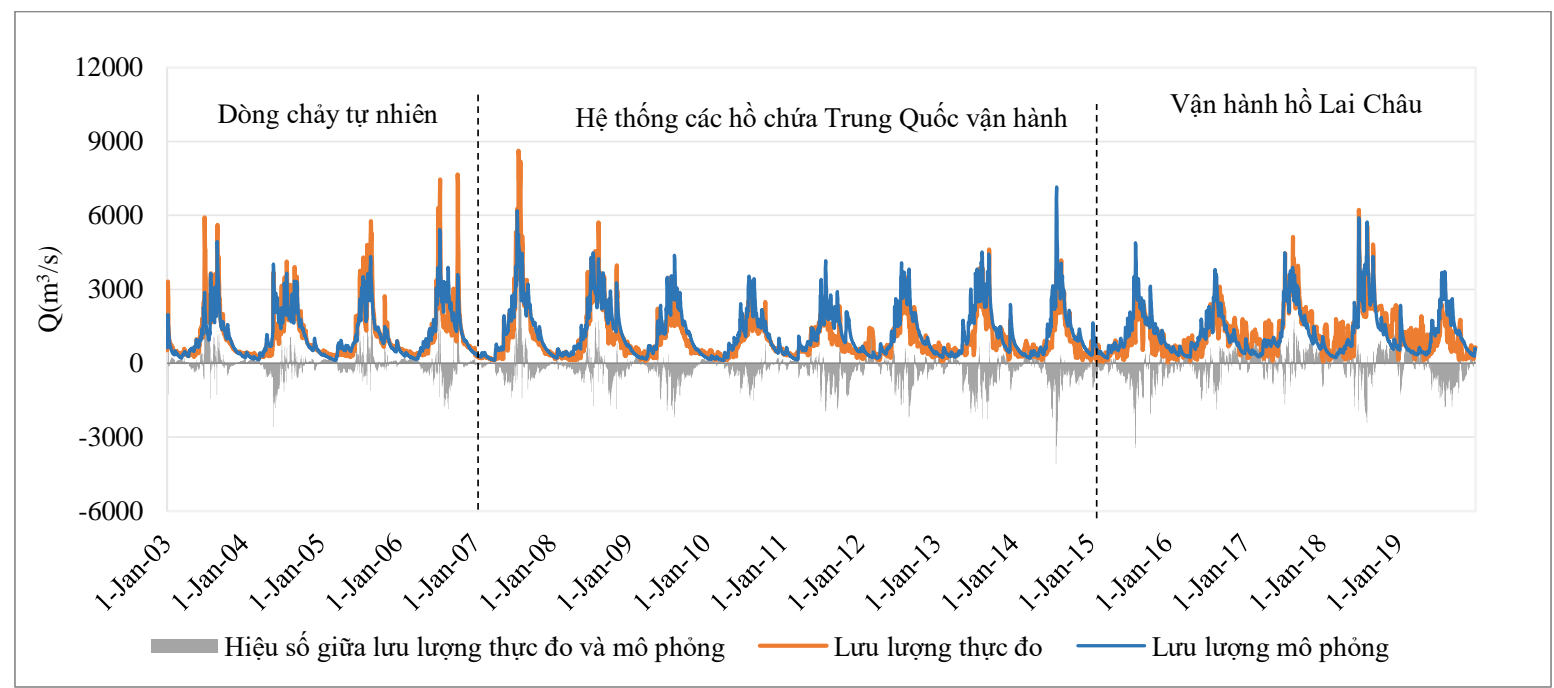

Hình 6. So sánh dòng chảy tự nhiên (mô phỏng) và dòng chảy thực đo trạm Lai Châu.

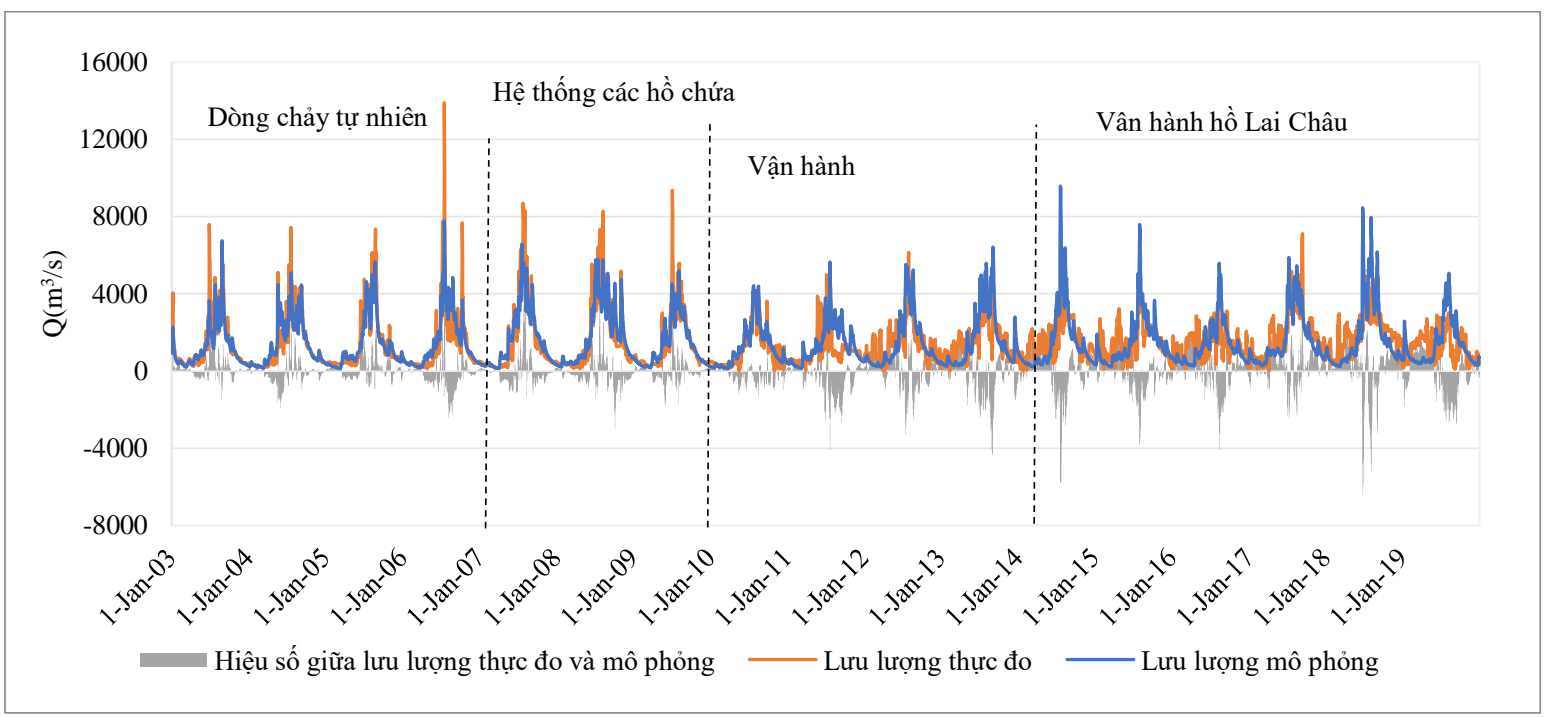

Hình 7. So sánh dòng chảy tự nhiên (mô phỏng) và dòng chảy thực đo trạm Tạ Bú. 
Để phân tích kỹ hơn sự thay đổi của dòng chảy trên sông Đà, nghiên cứu đã tiến hành tính toán biến động đóng góp của dòng chảy từng tháng và từng mùa vào dòng chảy năm trong trong các giai đoạn từ 1961-2020 sử dụng số liệu thực đo tại trạm Lai Châu và Tạ Bú. Các hình dưới đây thể hiện đóng góp của từng tháng và đóng góp của mùa mưa và mùa khô vào dòng chảy năm qua các thời kì. Các hình vẽ cho thấy thấy sự suy giảm tổng lượng dòng chảy qua các thời kì khi các hồ Trung Quốc và Việt Nam vận hành. So với thời kì dòng chảy tự nhiên (1961-2006), sau 2007 khi các hồ chứa Trung Quốc trên sông Đà được xây dựng và đi vào vận hành đã làm tăng đóng góp cho dòng chảy của các tháng mùa khô và giảm đóng góp cho các tháng mùa mưa. Sau khi các hồ Sơn La và Lai Châu vận hành, mức độ đóng góp dòng chảy mùa mưa tiếp tục giảm và mùa khô tiếp tục tăng, cụ thể:

Tại trạm Lai Châu (Hình 9), so với thời kì 1961-2006 thì từ 2007-2014 là thời kì chịu ảnh hưởng chính của hệ thống các hồ Trung Quốc. Tổng lượng dòng chảy thời kì này giảm mạnh, làm dòng chảy mùa khô tăng và mùa mưa dòng chảy giảm. Mùa khô, dòng chảy tăng từ 22,74\% (1961-2006) lên 29,34\% (2007-2014) trong khi mùa mưa tỷ lệ này giảm từ 77,26\% xuống 70,66\% tổng lượng dòng chảy. Từ năm 2015 ngoài tác động của hồ Trung Quốc trên dòng chính Việt Nam có thêm hồ Lai Châu hoạt động và đi vào điều tiết, các tháng mùa khô dòng chảy tăng cao và các tháng mùa mưa dòng chảy giảm mạnh so với các thời kì trước. Đóng góp dòng chảy của mùa mưa vào tổng dòng chảy năm giảm xuống còn $63,88 \%$ và của mùa khô tăng lên $36,12 \%$.

Tại trạm Tạ Bú, so sánh 2 thời kì từ 1961-2006 là thời kì dòng chảy tự nhiên thì từ năm 2007-2020 là thời kì chịu ảnh hưởng của toàn bộ các hồ chứa Trung Quốc và đặc biệt là sự điều tiết của các hồ chứa Việt Nam. Tổng lượng dòng chảy thời kì này giảm $2,99 \%$ khoảng 1 tỷ. $\mathrm{m}^{3}$ so với thời kì trước. Có 2 nguyên nhân chính dẫn đến tổng lượng dòng chảy năm bị suy giảm. Thứ nhất giai đoạn 2007-2020, đặc biệt là giai đoạn 2007-2009 là giai đoạn ít nước. Thứ hai là do khi các hồ chứa tích nước lượng nước tổn thất do bốc hơi và ngấm xuống đất tăng lên cũng làm giảm tổng lượng dòng chảy. Dòng chảy mùa khô tăng và dòng chảy mùa mưa giảm. Mùa mưa dòng chảy giảm từ $77,28 \%$ (1961-2006) xuống 65,75\% (2007-2020), mùa khô tăng từ 22,71\% lên 32,25\% (Hình 11). Theo tháng, đóng góp của tháng III vào dòng chảy năm tăng từ $1,91 \%$ lên $4,69 \%$ và của tháng IV tăng từ $2,03 \%$ lên $5,68 \%$. Các tháng dòng chảy lớn nhất vẫn tháng VII và VIII nhưng đóng góp cho dòng chảy giảm tương đối lớn từ $22,34 \%$ xuống $17,43 \%$ với tháng VII và từ $21,84 \%$ xuống 16,55\% với VIII (Hình 10).

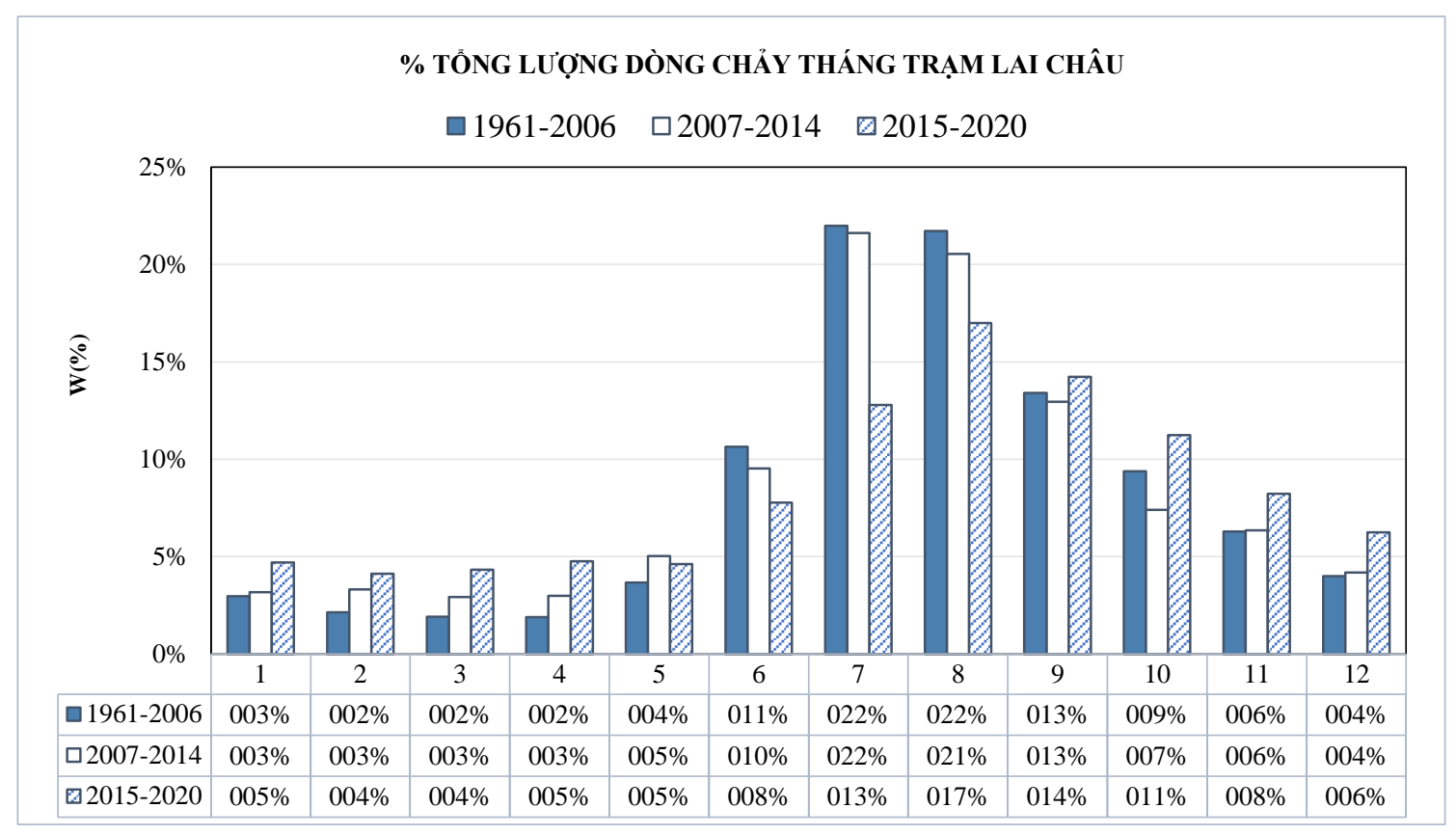

Hình 8. Đóng góp dòng chảy của từng tháng vào dòng chảy năm trạm Lai Châu. 

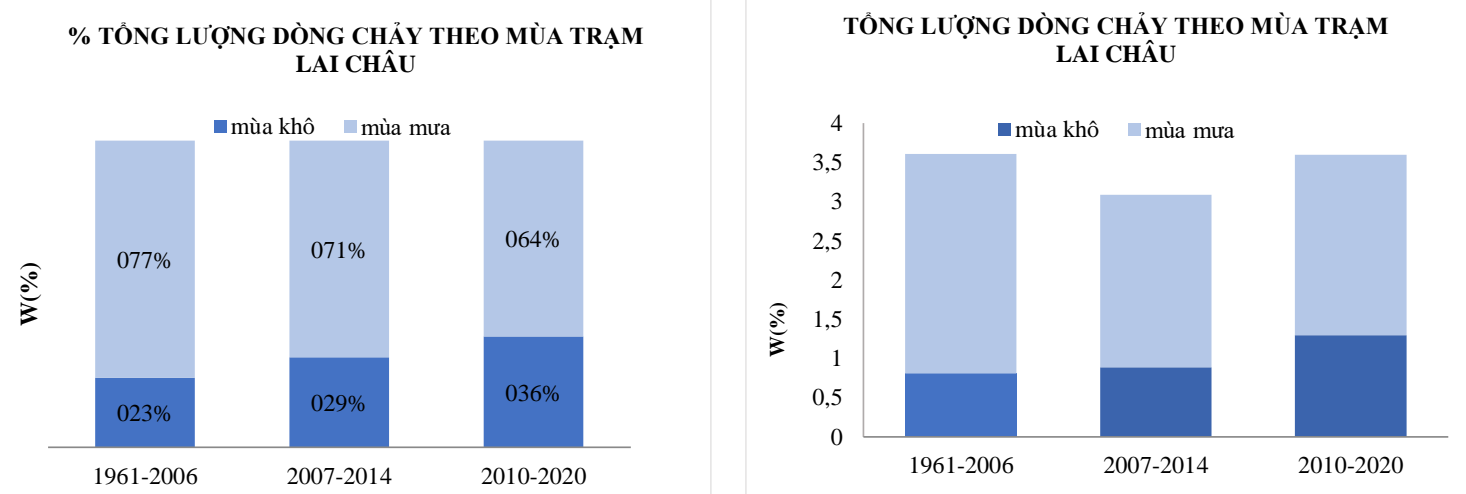

Hình 9. Đóng góp dòng chảy mùa mưa và mùa khô vào dòng chảy năm trạm Lai Châu.

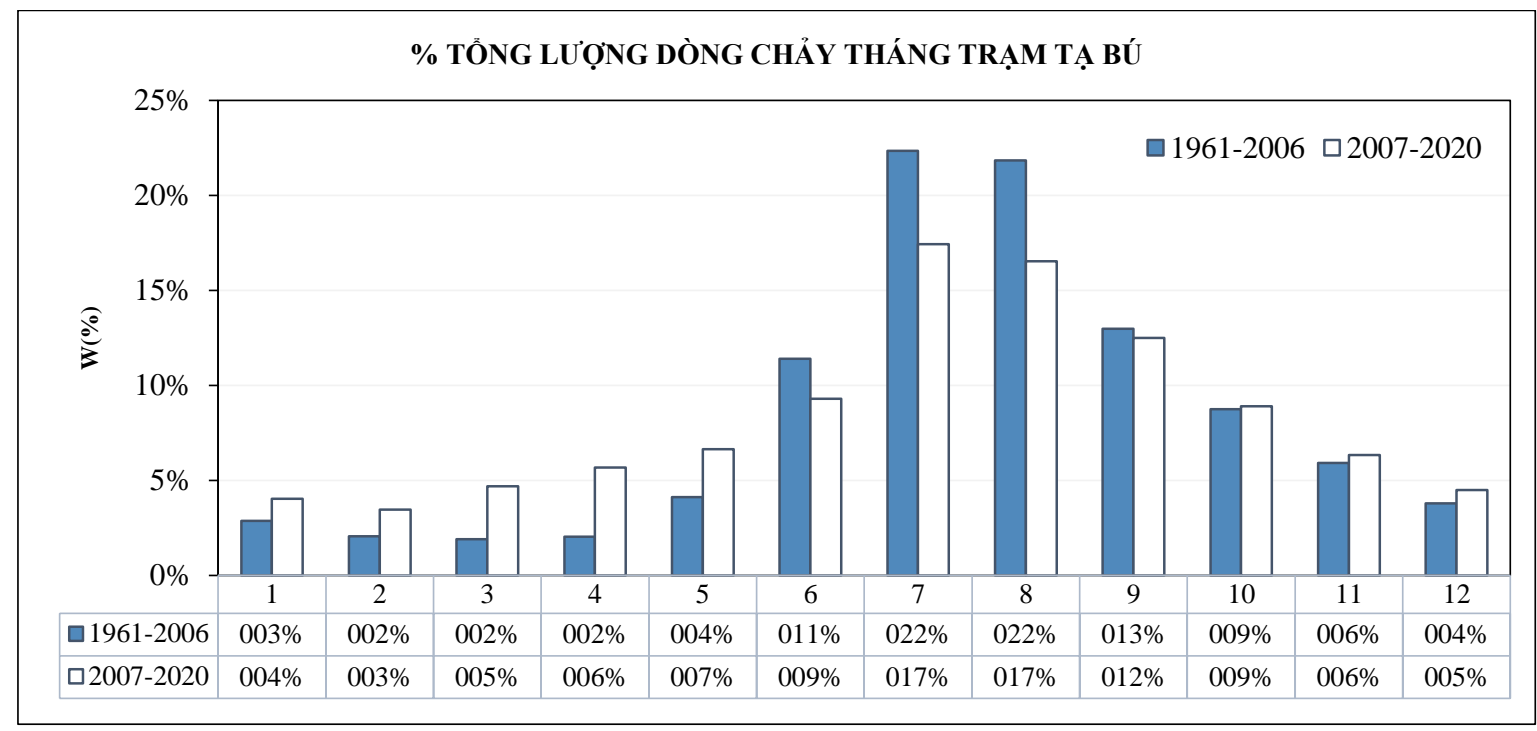

Hình 10. Đóng góp dòng chảy của từng tháng vào dòng chảy năm tại Tạ Bú.
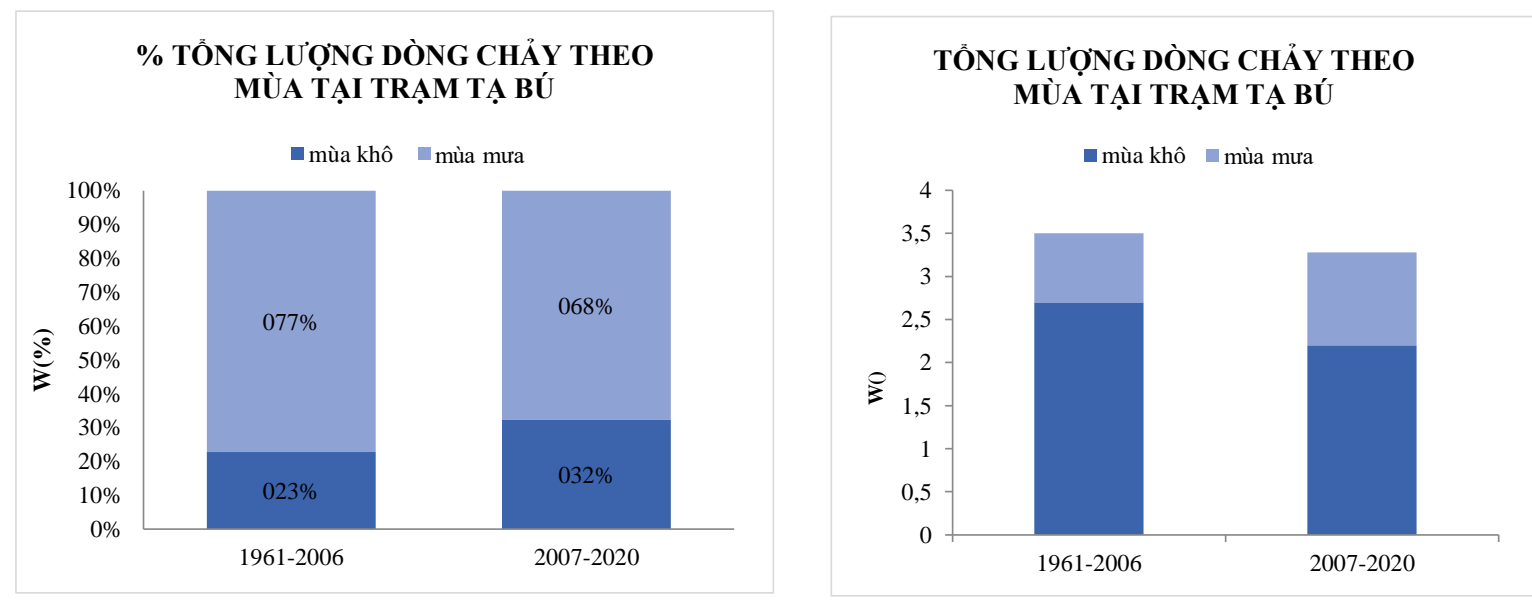

Hình 11. Đóng góp dòng chảy mùa mưa và mùa khô vào dòng chảy năm tại Tạ Bú.

\section{Kết luận}

Nghiên cứu đã đánh giá được sự thay đổi dòng chảy trên sông Đà dưới tác động riêng rẽ và tổng hợp của các hệ thống hồ chứa Trung Quốc và Việt Nam qua phân tích số liệu dòng chảy thực đo và mô phỏng dòng chảy trước và sau năm 2007 khi các hệ thống hồ chứa đi vào vận hành. Kết quả nghiên cứu cho thấy sai số tổng lượng giữa dòng chảy tự 
nhiên mô phỏng và thực đo tăng lên đáng kể khi các hồ chứa đi vào hoạt động, chứng tỏ chế độ dòng chảy tự nhiên đã bị thay đổi tương đối lớn. Sau 2007 khi các hệ thống hồ chứa đi vào hoạt động làm tăng đóng góp dòng chảy mùa khô và giảm đóng góp dòng chảy mùa mưa, dòng chảy năm có sự suy giảm rõ rệt qua các thời kì. Tại trạm Lai Châu, mùa khô, dòng chảy tăng từ 22,74\% (1961-2006) lên 29,34\% (2007-2014) khi các hồ chứa Trung Quốc hoạt động và lên $36,12 \%$ khi có thêm các hồ chứa trên lãnh thổ Việt Nam. Tại trạm Tạ Bú, dòng chảy mùa mưa giảm từ 77,28\% (1961-2006) xuống 65,75\%, mùa khô tăng từ $22,71 \%$ lên 32,25\% trong giai đoạn các hồ chứa Việt Nam và Trung Quốc đi vào vận hành (2007-2020). Tổng lượng dòng chảy về đến Tạ Bú giảm 1 tỉ $\mathrm{m}^{3}$ so với thời kì trước do giai đoạn từ 2007-2020 là giai đoạn ít nước cùng với việc tích nước của các hồ chứa với dung tích lớn trên thượng nguồn lưu vực, lượng nước thất thoát do bốc hơi và ngấm trong lòng hồ làm cho dòng chảy bị suy giảm. Nghiên cứu này góp phần làm sáng tỏ hơn tác động của các hệ thống hồ chứa đến sự thay đổi dòng chảy trên lưu vực sông Đà, nâng cao hiệu quả vận hành của các hồ chứa và quản lý tổng hợp tài nguyên nước trên lãnh thổ Việt Nam, đảm bảo an ninh nguồn nước trong điều kiện biến đổi khí hậu và gia tăng hoạt động khai thác tài nguyên nước của các quốc gia thượng nguồn. Những đánh giá trong nghiên cứu dựa vào so sánh kết quả mô phỏng từ mô hình HEC-HMS sử dụng nguồn số liệu mưa vệ tinh IMERG cung cấp từ 2003 cho đến nay và số liệu các trạm bốc hơi trên lưu vực thuộc lãnh thổ Việt Nam. Trong những nghiên cứu tiếp theo, chúng tôi sẽ xem xét sử dụng các số liệu bốc hơi từ các nguồn số liệu toàn cầu, giúp cải thiện độ chính xác của kết quả mô phỏng dòng chảy trên phần lãnh thổ nước ngoài vào Việt Nam.

Đóng góp của tác giả: Xây dựng ý tưởng nghiên cứu: T.A.P.; Lựa chọn phương pháp nghiên cứu: T.A.P.; Xử lý số liệu: B.H.L.; Viết bản thảo bài báo: T.A.P., B.H.L.; Chỉnh sửa bài báo: T.A.P., B.H.L.

Lời cam đoan: Tập thể tác giả cam đoan bài báo này là công trình nghiên cứu của tập thể tác giả, chưa được công bố ở đâu, không được sao chép từ những nghiên cứu trước đây; không có sự tranh chấp lợi ích trong nhóm tác giả.

\section{Tài liệu tham khảo}

1. Ngo, L.A.; Masih, I.; Jiang, Y.; Douven, W. Impact of reservoir operation and climate change on the hydrological regime of the Sesan and Srepok Rivers in the Lower Mekong Basin. Clim. Change 2018, 149(1), 107-119.

2. Zhaohua, S.; Xiang, F.; Xuefeng, C. Assessing the impacts of reservoir operation on downstream water diversions using a simplified flow model. Hydrol. Sci. J. 2019, 64(12), 1488-1503.

3. Tô, Q.T. Phân tích ảnh hưởng của các hồ đập thượng lưu đến sự thay đổi thủy văn dòng chảy mùa khô về châu thổ sông Mê Công, 2016.

4. Tô, Q.T.; Tăng, Đ.T. Nghiên cứu đánh giá thay đổi thủy văn dòng chảy về châu thổ Mê Công qua chuỗi số liệu lịch sử từ 1924 đến nay. Tạp chí Khoa họ và Công nghệ Thủy lợi 2014, 17-23.

5. Giáp, N.Đ. Tác động của hệ thống hồ chứa thượng nguồn đến sự thay đổi thủy văn, thủy lực và lòng dẫn hạ du. Tạp chí Khoa hoc và Công nghệ thuỷ lợi 2016, 32, 1-8.

6. Châu, N.L.C. Đánh giá tác động của hệ thống hồ chứa trên sông Đà, sông Lô đến dòng chảy mùa cạn hạ lưu sông Hồng và đề xuất giải pháp đảm bảo nguồn mở cho hạ du. Trung tâm Dư báo KTTV TW, 2010, tr. 244.

7. Tuyển, H.M. Đề tài nghiên cứu khoa học cấp bộ. Nghiên cứu diễn biến, xác định các nguyên nhân thay đổi tỷ lệ phân phối dòng chảy sông Hồng sang sông Đuống và để xuất định hướng giải pháp nhằm đảm bảo tỷ lệ phân phối dòng chảy hợp lý. 2013. 
8. Anh, L.T. Đề tài nghiên cứu khoa học cấp bộ. Nghiên cứu tác động của việc sử dụng nước phía thượng lưu đến tài nguyên nước lưu vực sông Hồng, 2011.

9. Hà V.K.; Huệ, V.M. Phân tích ảnh hưởng của các hồ chứa thượng nguồn trên địa phận Trung Quốc đến dòng chảy hạ lưu sông Đà, sông Thao. Tạp chi Khoa học thuỷ lợi và Môi trường 2012, 38, 3-8.

10. Huệ, V.M.; Phượng, Đ.K. Nghiên cứu đánh giá tác động của các hồ chứa Lai Châu, Sơn La và Hòa Bình đến dòng chảy mùa kiệt trên sông Đà, 2017.

11. Anh, T.V. Nghiên cứu đánh giá lượng dòng chảy sông Đà từ Trung Quốc vào Việt Nam phục vụ cho bài toán quy hoạch và quản lý tài nguyên nước sông Đà. Tạp Chí Khi tương thủy văn 2017, 57, 4-9.

12. Phương, T.T.; Dũng, L.H.; Tác động của hệ thống hồ chứa lớn đến dòng chảy trên hệ thống sông Hồng. Tạp chí Khoa học và Công nghệ Việt Nam 2017, 18(7), 5-9.

13. https://www.hec.usace.army.mil/software/hec-geohms/.

14. https://www.hec.usace.army.mil/software/hec-hms/downloads.aspx.

15. Fleming, M.J. User's manual, hydrologic modeling system HEC-HMS Version 3.5. HQ US Army Corps of Engineers, 2001, 1-318.

16. HEC. Applications Guide Hydrologic Modeling System HEC-HMS V.2.01. US Army Corps of Enginenring Center, 2008, 118, 11-107.

17. Evaluation of HEC-HMS and WEPP for simulating watershed runoff using remote sensing and geographical information system.

18. Li, Z. Watershed modeling using arc hydro based on DEMs: a case study in Jackpine watershed. Environ. Syst. Res. 2014, 3, 11.

19. Hướng dẫn sử dụng mô hình HEC-HMS, Giáo trình, Đại học thủy lợi, 2005.

20. https://gpm.nasa.gov/data/imerg.

21. Nguyên, L.B. Nghiên cứu đánh giá sản phẩm mưa từ nhiệm vụ đo mưa toàn cầu (GPM) cho miền Bắc Việt Nam, 2020.

22. Nam, B.C. Nghiên cứu đánh giá dữ liệu mưa quan trắc vệ tinh từ GPM và PERSIANN phục vụ cảnh báo mưa thành phố Hồ Chí Minh. Tạp Chí Khí tượng thüy văn 2017, 679, 27-33.

23. Xuân,T.T.; Tuyển; H.M. Vai trò của hồ chứa trong khai thác, quản lý tài nguyên nước mặt ở Việt Nam. Nhà xuất bản Khoa học và kỹ Thuật 2019, 183(19-28), 6777.

\section{Assessment of the impact of reservoirs on flow variations on the Da River}

\section{Bui Huyen Linh', Tran Anh Phuong ${ }^{1 *}$}

${ }^{1}$ Water Resouces Institute, Ministry of Natural Resources and Environment; wri@monre.gov.vn; phuongtran.monre@gmail.com; linhb.dctv@gmail.com

Abstract: This research evaluates the influence of reservoirs inside and outside the territory on the flow change on $\mathrm{Da}$ river to $\mathrm{Ta} \mathrm{Bu}$ station by statistical method and using HEC-HMS model to simulate natural flow numerically Satellite rainfall data (IMERG) is compared with real measured data (when the reservoirs come into operation) to assess flow changes during the flood and dry seasons and annual flow. The results show that the decrease in the total annual flow when the reservoirs come into operation increases the dry season flow and decreases the flood season flow.

Keywords: Da River; Reservoirs; Flow regime; Global saterllite precipitation; HECHMS. 